\title{
APPLICATION OF FOURIER SERIES IN THE ANALYSIS OF NON-SINUSOIDAL ALTERNATING VALUES
}

\author{
Ladislav Havaš, Damira Keček, Veljko Kondić
}

Subject review

Analyses of alternating electrical circuits in electrical engineering are usually based on assumption that currents and voltages are sinusoidal values. Such assumption allows analysis of electrical networks by symbolic mathematical calculation. It also allows the application of vector diagrams in representing relationship of the analyzed electrical values. In practice, periodic non sinusoidal values are sometimes found. For solving such values symbolic mathematical calculation and vector diagrams cannot be used. In this paper is shown how such non sinusoidal periodic values can be separated, by applying Fourier series, into infinite series which contains a constant term and infinitely many harmonic components. That way allows all the acquired knowledge and methods for solving sinusoidal periodic values to still be used.

Keywords: alternating electrical circuits; Fourier series; higher harmonics; non sinusoidal alternating values

Primjena Fourierovih redova u analizi nesinusoidalnih izmjeničnih veličina

Pregledni članak

Analize izmjeničnih strujnih krugova u elektrotehnici su najčešće bazirane na pretpostavci da su struje i naponi sinusoidalne veličine. Takva pretpostavka omogućuje analizu električnih mreža simboličkim matematičkim računom te primjenu vektorskih dijagrama u prikazivanju odnosa analiziranih električnih veličina. U praksi se ponekad susreću periodičke nesinusoidalne veličine za čije rješavanje se ne mogu koristiti simbolički matematički račun i vektorski dijagrami. U ovom je radu prikazano kako se takve nesinusoidalne periodičke veličine mogu primjenom Fourierovog reda rastaviti na beskonačni red koji sadrži konstantan član i beskonačno mnogo harmoničkih komponenata. Na taj način omogućeno je da se sva usvojena znanja i metode rješavanja sinusoidalnih periodičkih veličina mogu i dalje koristiti.

Ključne riječi: Fourierov red; izmjenični strujni krugovi; nesinusoidalne periodičke veličine; viši harmonici

\section{Introduction}

In various mathematical applications composite functions are approximated by simpler functions that are more suitable for further calculation $[1,2]$. In that way, to solve numerous technical and physical problems, periodic functions need to be converted in series according to trigonometric functions, i.e. to display them in the form of a sum of sine and cosine functions of different amplitudes and frequencies [3].

For solving and the analysis of alternating electrotechnical networks it is suitable to use complex calculation, wherein the voltage and the current are shown by phasors. Phasors are composite numbers that are used to display sinusoidal values in a complex plane. The length of those vectors that rotate counter-clockwise with angle velocity represents the maximal value of voltage or current, while the projection of that vector (phasor) on the vertical axis gives the current value of voltage or current. The possibility of application of phasors in the analysis of electrical values is directly dependent on their sinusoidal nature. In case of presence of periodic signals that do not have sinusoidal shape, the conversion of all nonsinusoidal values into sinusoidal is the necessary precondition for using complex calculation in the analysis of alternating circuits [4].

\section{Fourier series}

Let $f:[-L, L] \rightarrow R$ be a periodic function with period $T=2 L$. Further, let $L^{2}[-L, L]$ be a space of square integrable functions on the segment $[-L, L]$ i.e.

$$
L^{2}[-L, L]=\left\{f:[-L, L] \rightarrow R ; \int_{-L}^{L}|f(x)|^{2} \mathrm{~d} x<\infty\right\}(1)
$$

The inner product of functions $f$ and $g$ on the space $L^{2}[-L, L]$ is defined by formula

$\langle f, g\rangle=\int_{-L}^{L} f(x) g(x) \mathrm{d} x$.

Functions $f$ and $g$ are orthogonal if their inner product is zero, i.e. if

$\langle f, g\rangle=\int_{-L}^{L} f(x) g(x) \mathrm{dx}=0$.

Trigonometrics series of the form

$\frac{a_{0}}{2}+\sum_{n=1}^{\infty}\left(a_{n} \cdot \cos \frac{n \pi x}{L}+b_{n} \cdot \sin \frac{n \pi x}{L}\right)$

are used for the approximation of the periodic functions.

Trigonometric development (4) of the periodic function $f$ on the interval $[-L, L]$ is a development of the function $f$ in Fourier series, i.e. development of the function $f$ by continuous functions

$\frac{1}{2}, \cos \frac{\pi x}{L}, \sin \frac{\pi x}{L}, \cdots, \cos \frac{n \pi x}{L}, \sin \frac{n \pi x}{L}, \cdots$

From space $L^{2}[-L, L]$ the sequence of functions (5) is orthogonal over an interval $[-L, L]$ which means that the integral of the product of any two different functions in (5) over the interval $[-L, L]$ is zero, while the integral of the square of each function in (5) is different from zero. Coefficients $a_{0}, a_{n}$ and $b_{n}, n \geq 1$ of trigonometrics series (4) are determined by using the orthogonality of functions (5) and are calculated by formulas 
$a_{0}=\langle f, 1\rangle=\frac{1}{L} \int_{-L}^{L} f(x) \mathrm{d} x$,

$a_{n}=\left\langle f, \cos \frac{n \pi x}{L}\right\rangle=\frac{1}{L} \int_{-L}^{L} f(x) \cdot \cos \frac{n \pi x}{L} \mathrm{~d} x, n \geq 1$,

$b_{n}=\left\langle f, \sin \frac{n \pi x}{L}\right\rangle=\frac{1}{L} \int_{-L}^{L} f(x) \cdot \sin \frac{n \pi x}{L} \mathrm{~d} x, n \geq 1$.

Numbers $a_{0}, a_{n}$ and $b_{n}, n \geq 1$ are called Fourier coefficient of $f$, while trigonometrics series (4) with those coefficients is called Fourier series of $f$.

In a case of an even or odd function $f$ defined on simetric interval $[-L, L]$ above formulas are simplifying. Namely, if $f$ is an even function, that is, $f(-x)=f(x)$, for all $x$, then $b_{n}=0$, for all $n$. Fourier series of function $f$ in that case contains only cosine functions as follows

$f(x)=\frac{a_{0}}{2}+\sum_{n=1}^{\infty} a_{n} \cdot \cos \frac{n \pi x}{L}$,

where

$a_{0}=\frac{2}{L} \int_{0}^{L} f(x) \mathrm{d} x$

and

$a_{n}=\frac{2}{L} \int_{0}^{L} f(x) \cdot \cos \frac{n \pi x}{L} \mathrm{~d} x, n \geq 1$.

If $f$ is an odd function, that is, $f(-x)=-f(x)$, for all $x$, then $a_{n}=0$, for all $n$. Fourier series of an odd function $f$ on interval $[-L, L]$ contains only sine functions as follows

$f(x)=\sum_{n=1}^{\infty} b_{n} \cdot \sin \frac{n \pi x}{L}$,

where

$b_{n}=\frac{2}{L} \int_{0}^{L} f(x) \cdot \sin \frac{n \pi x}{L} \mathrm{~d} x, n \geq 1$.

All of the above formulas are derived for the case of the periodic function observed on simetric interval $[-L, L]$. For the general case, when the function is observed on interval $[a, b]$, Fourier series of periodic function $f$ with period $T=b-a$ is

$f(x)=\frac{a_{0}}{2}+\sum_{n=1}^{\infty}\left(a_{n} \cdot \cos \frac{2 n \pi x}{T}+b_{n} \cdot \sin \frac{2 n \pi x}{T}\right)$,

while the Fourier coefficients are calculated according to formulas

$a_{0}=\frac{2}{T} \int_{a}^{b} f(x) \mathrm{d} x$

$a_{n}=\frac{2}{T} \int_{a}^{b} f(x) \cdot \cos \frac{2 n \pi x}{T} \mathrm{~d} x, n \geq 1$,

$b_{n}=\frac{2}{T} \int_{a}^{b} f(x) \cdot \sin \frac{2 n \pi x}{T} \mathrm{~d} x, n \geq 1$.

More detailed information about Fourier series the reader may find in $[5,6,7]$.

\section{Transformation of non-sinusoidal values into infinite series}

As mentioned in the introduction, alternating networks can be solved by using complex calculation, wherein the voltage and the current are shown by phasors, which cannot be directly used if value does not have sinusoidal shape. Therefore, all non sinusoidal periodic values have to be expanded into infinite series of form

$u=U_{0}+U_{1 \max } \cdot \sin \left(\omega t+\beta_{u 1}\right)+U_{2 \max } \cdot \sin (\omega t+$

$\left.\beta_{u 2}\right)+\cdots+U_{k \max } \cdot \sin \left(\omega t+\beta_{u k}\right)+\cdots$

which contains a constant term and infinitely many harmonic components of different amplitudes $U_{i \text { max }}, i \geq$ 1 , frequencies $\omega t$ and phases $\beta_{u i}, i \geq 1$. With increasing frequency, amplitudes of the sinusoidal terms are smaller, so the nonsinusoidal value can be written with a first few terms of the infinite series with sufficient accuracy.

According to addition theorem

$\sin (\alpha+\beta)=\sin \alpha \cdot \cos \beta+\cos \alpha \cdot \sin \beta$

Eq. (18) becomes

$u=U_{0}+\sum_{k=1}^{\infty}\left(A_{k \max } \cdot \cos (k \omega t)+B_{k \max } \cdot \sin (k \omega t)\right)$

where

$A_{k \max }=U_{k \max } \cdot \sin \beta_{u k}, B_{k \max }=U_{k \max } \cdot \cos \beta_{u k}$.

Constants in equations (20) and (21) are, by formulas (15), (16) and (17), calculated according to

$U_{0}=\frac{1}{T} \int_{0}^{T} u \mathrm{~d} t$

$A_{k \max }=\frac{2}{T} \int_{0}^{T} u \cdot \cos (k \omega t) \mathrm{d} t$,

$B_{k \max }=\frac{2}{T} \int_{0}^{T} u \cdot \sin (k \omega t) \mathrm{d} t$,

while

$U_{k \max }=\sqrt{A_{k \max }^{2}+B_{k \max }^{2}}$

and

$\tan \beta_{u k}=\frac{A_{k \max }}{B_{k \max }}$

\section{Analysis of square wave signal}

Distinctive non sinusoidal patterns of voltages are square and triangular. Those voltages are composed of a larger number of sinusoidal voltages with different frequencies and amplitudes (primary wave and higher harmonics). Primary wave has the same frequency as analysed non sinusoidal signal, while the other sinusoidal terms have significantly greater frequencies $[8,9]$.

In this paper will be shown how, by applying Fourier's series, square wave voltage signal can be 
analysed, what is shown in Fig. 1. According to formula (22), what can be seen from Fig. 1, this voltage does not contain DC component. Due to that, constant in formula (20), is zero.

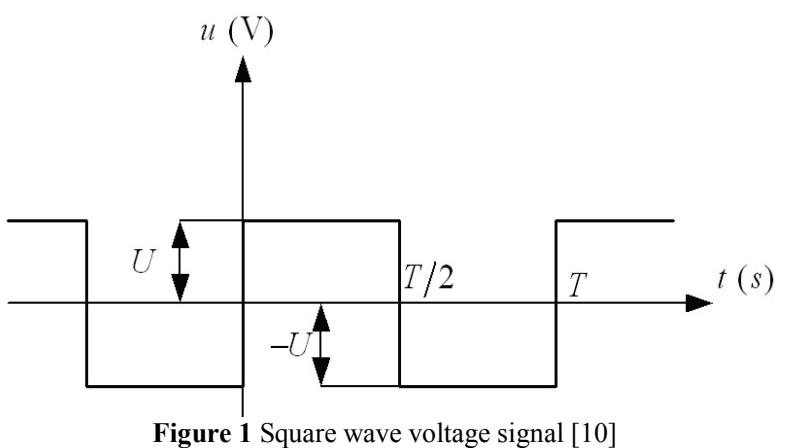

\subsection{Calculation of constant terms}

Since $A_{1 \mathrm{max}}=0$, it is necessary to calculate only

$B_{1 \max }=\frac{2}{T} \int_{0}^{\frac{T}{2}} U \cdot \sin (\omega t) \mathrm{d} t-\frac{2}{T} \int_{\frac{T}{2}}^{T} U \cdot \sin (\omega t) \mathrm{d} t=$

$=\left.\frac{2 \cdot U}{T} \cdot\left(-\frac{1}{\omega}\right) \cdot \cos (\omega t)\right|_{0} ^{\frac{T}{2}}-\left.\frac{2 \cdot U}{T} \cdot\left(-\frac{1}{\omega}\right) \cdot \cos (\omega t)\right|_{\frac{T}{2}} ^{T}=$

$=-\frac{2 \cdot U}{T \cdot \omega} \cdot\left(\cos \left(\frac{2 \pi}{T} \cdot \frac{T}{2}\right)-1\right)+\frac{2 \cdot U}{T \cdot \omega} \cdot\left(\cos \left(\frac{2 \pi}{T} \cdot T\right)-\right.$

$\left.\cos \left(\frac{2 \pi}{T} \cdot \frac{T}{2}\right)\right)=\frac{4 \cdot U}{T \cdot \omega}+\frac{4 \cdot U}{T \cdot \omega}=\frac{8 \cdot U}{T \cdot \frac{2 \pi}{T}}=\frac{4 \cdot U}{\pi}$.

Therefore, $U_{1 \max }=\frac{4 \cdot U}{\pi}$.

Since $u(-t)=-u(t)$ is non sinusoidal dimension, it does not contain cosine terms. Since, $u\left(t+\frac{T}{2}\right)=-u(t)$, is non sinusoidal dimension, it only contains odd terms. Therefore, the square wave voltage in Fig. 1 has only sinusoidal odd terms.

Since all the amplitudes of the sinusoidal terms with increase in frequency are declining, it is easy to mathematically prove the fact that amplitude of the third harmonic term is three times smaller than amplitude of the primary term, and amplitude of the fifth harmonic term is five times smaller than the primary term and so on.

It is evident that amplitudes of the higher harmonics are declining rapidly, therefore, non sinusoidal dimensions can be recorded, with decent accuracy, with only first few terms of the infinite series. Thus, Fourier's series for voltage, according to Fig. 1, is

$u=\frac{4 \cdot U}{\pi} \cdot\left(\sin (\omega t)+\frac{1}{3} \sin (3 \omega t)+\frac{1}{5} \sin (5 \omega t)+\cdots\right)$.

\subsection{Transformation of bipolar signal}

Let $U=\frac{U_{1} \cdot \sqrt{2} \cdot \pi}{4}$ be on interval $0<t<\frac{T}{2}$ an $\mathrm{d} U=$ $-\frac{U_{1} \cdot \sqrt{2} \cdot \pi}{4}$ on interval $\frac{T}{2}<t<T$, where $U_{1}$ stands for effective value of the primary harmonic term. If we consider only few first terms (until ninth harmonic; Fig. 2) graphical representation in Fig. 3 looks like square wave voltage. (Simulation has been made by Software: Electronics Workbench EWB 4.1).

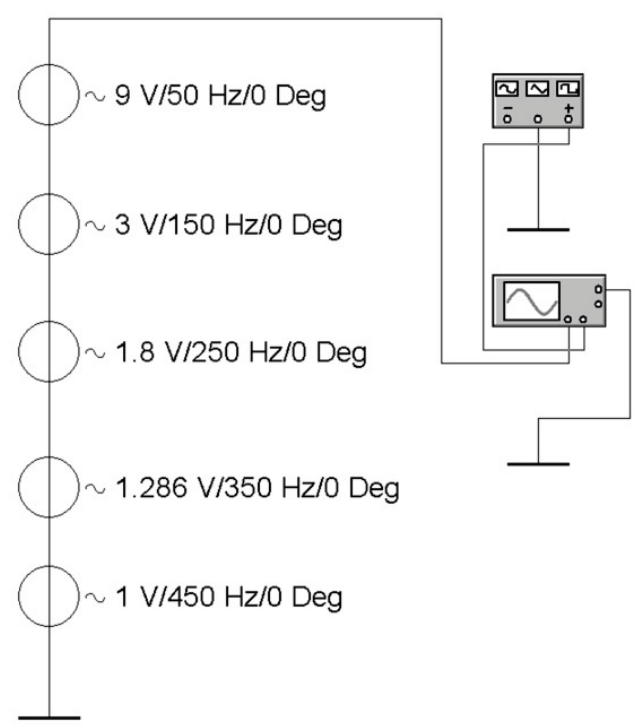

Figure 2 Simulation in EWB 4.1

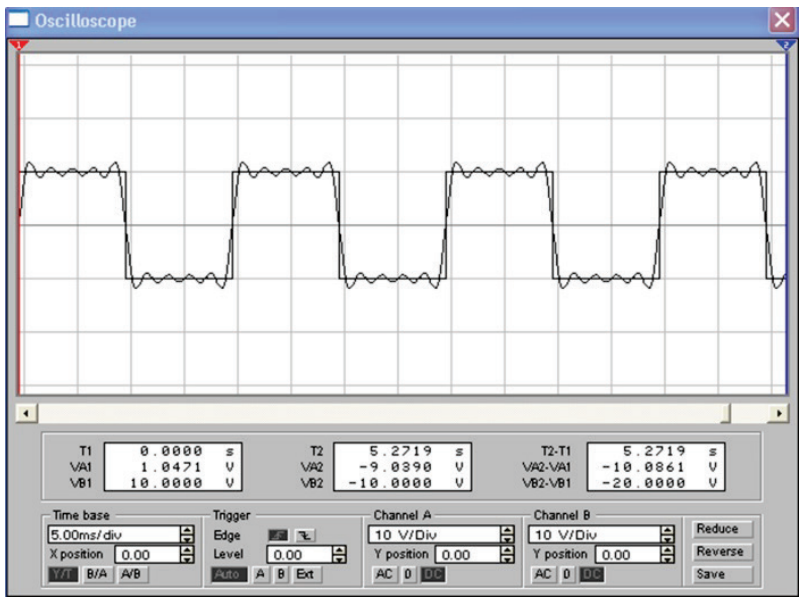

Figure 3 Representation of square wave voltage signal

\subsection{Transformation of unipolar signal}

For the practice, unipolar square wave voltage signal is also interesting, which is shown in Fig. 4.

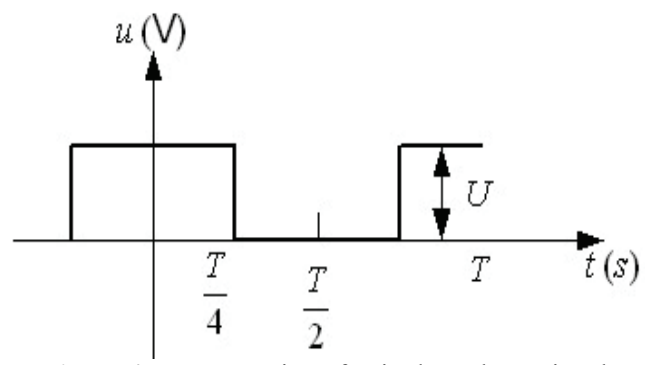

Figure 4 Representation of unipolar voltage signal

Relation $u(-t)=u(t)$ shows that the function does not contain sinusoidal terms. Development of this specific function into Fourier's series goes in the following way

$u=\frac{U}{2}+\frac{2 \cdot U}{\pi} \cdot\left(\cos (\omega t)-\frac{1}{3} \cdot \cos (3 \omega t)+\cdots\right)$. 
DC terms is represented as $U_{0}$. From the formula (30) it can be seen that such function contains constant term, so as cosine harmonic terms with both positive and negative signs.

A short example will be used as a display of the calculations of the DC term, as well as a few higher harmonics of such Fourier's series.

Let $U=10 \mathrm{~V}$. DC term is $5 \mathrm{~V}$. The amplitude of primary harmonic term is $U_{1 \max }=\frac{2 \cdot 10}{\pi}=6,366 \mathrm{~V}$. The effective value is $U_{1}=\frac{2 \cdot 10}{\pi \cdot \sqrt{2}}=4,5 \mathrm{~V}$. Calculated primary terms and first few harmonics are shown in Tab. 1.

Table 1 Calculated primary terms of Fourier's series

\begin{tabular}{|l|c|}
\hline \multicolumn{1}{|c|}{ Fourier's series term } & Value (V) \\
\hline DC & $+5,000$ \\
\hline First harmonic term & $+4,500$ \\
\hline The third & $-1,500$ \\
\hline The fifth & $+0,900$ \\
\hline The seventh & $-0,643$ \\
\hline The ninth & $+0,500$ \\
\hline
\end{tabular}

\section{Conclusion}

In electrical circuits we often find non sinusoidal alternating values that are extremely important in transmission and analysis of different signals. Unlike sinusoidal alternating values, they cannot be displayed by using vectors and complex numbers, but only as continuous time (or discrete) functions.

In this paper it is shown that such functions can be, using Fourier transformation, distinguished to DC component and to a series of alternating components (harmonics). Since nowadays the importance of application of Fourier transformation in the analysis of electrical networks is emphasized [11], the introductory chapters of this paper mathematically explain Fourier series and the calculation of its coefficients.

Unlike discrete Fourier transformations [12, 13, 14], in this paper is shown, based on the example of continuous time non sinusoidal functions (square wave signals), the usage of continuous time Fourier transformation. Such transformed signal is possible to analyze by using conventional complex/vector methods and available software for the analysis of electrical networks [15].

\section{References}

[1] Folland, G. B. Fourier Analysis and Its Applications. Brooks/Cole Publishing Company, Pacific Grove, California, 1992.

[2] Rabiner, L. R.; Gold, B. Theory and Application of Digital Signal Processing. Prentice Hall, 1975.

[3] Gasquet, C.; Witomski, P. Fourier Analysis and Applications: Filtering, Numerical Computation, Wavelets. Springer, New York, 1998.

[4] Sabah, N. H. Electric Circuits and Signals. CRC Press; $1^{\text {st }}$ edition. CRC Press, Boca Raton, Florida, 2008.

[5] Ivanšić, I. Fourier series and integral, differential equations (in Croatian). Faculty of Electrical Engineering, Zagreb, 1982.

[6] Kreyszig, E. Advanced engineering mathematics, $10^{\text {th }}$ Edition. John Wiley \& Sons, New York, 2010.
[7] Bremaud, P. Mathematical Principles of Signal Processing: Fourier and Wavelet Analysis. Springer, New York, 2002.

[8] Pinter, V. Basics of Electrical Engineering, Book two (in Croatian). Tehnička knjiga Zagreb, Zagreb, 1984.

[9] Anumaka, M.C. Analysis of Electric Circuits Using Fourier Series. // International Journal of Engineering and Innovative Technology. 1, 5(2012), pp. 125-128.

[10] Havaš, L.; Huđek, J. Basics of Electrical Engineering 1 and 2 (in Croatian). University North, Varaždin, 2012.

[11] Proakis, J. G.; Manolakis, D. G. Digital Signal Processing. Prentice Hall, 2006.

[12] Sanjit, K. M. Digital Signal Processing, A Computer-Based Approach. University of California, Santa Barbara, 1998.

[13] Oppenheim, A. V.; Schafer, R. W. Discrete-Time Signal Processing. Prentice Hall PTR, 2009.

[14] Stearns, S. D. Signal Processing Algorithms in Matlab. Prentice Hall, 1996.

[15] Kuo, S. M.; Morgan, R.D. Active Noise Control Systems: Algorithms and DSP Implementations. Wiley \& Sons, 1996.

\section{Authors' addresses}

Ladislav Havaš, Ph.D.

University North

104. brigade 3, 42000 Varaždin, Croatia

E-mail: ladislav.havas@unin.hr

Damira Keček, B.S.

University North

104. brigade 3, 42000 Varaždin, Croatia

E-mail: damira.kecek@unin.hr

Veljko Kondić, B.S.

University North

104. brigade 3, 42000 Varaždin, Croatia

E-mail: veljko.kondic@unin.hr 